\title{
ANALISIS HUBUNGAN LAMA PENGGUNAAN DAN USIA AKSEPTOR SUNTIK DMPA TERHADAP RISIKO OBESITAS DI PUSKESMAS PERUMNAS II PONTIANAK
}

\section{ANALYSIS OF CORRELATION DURATION OF USE AND AGE OF ACCEPTORS DMPA INJECTION TO THE RISK OF OBESITY AT PERUMNAS II PONTIANAK PUBLIC HEALTH CARE}

\author{
Nurmainah*, Syaazaratul Qamelia Innas \\ Program Studi Farmasi, Fakultas Kedokteran, Universitas Tanjungpura Pontianak, \\ Kalimantan Barat, Indonesia \\ *Penulis Koresponding, e-mail: nurmainah@ @harm.untan.ac.id
}

\begin{abstract}
ABSTRAK
Kontrasepsi suntik adalah obat hormonal yang digunakan untuk mencegah kehamilan dengan jalan menyuntikkan obat tersebut pada wanita subur. Kontrasepsi hormonal dapat meningkatkan berat badan. Tujuan penelitian ini dilakukan adalah untuk menganalisis hubungan antara lama penggunaan dan usia akseptor terhadap kejadian risiko obesitas. Penelitian ini merupakan penelitian observasional dengan rancangan penelitian potong lintang (cross sectional) bersifat analitik. Populasi dalam penelitian ini adalah seluruh akseptor baru kontrasepsi suntik 3 bulan DMPA di Puskesmas Perumnas II Pontianak pada bulan Januari 2018 hingga Maret 2019. Variabel dari penelitian ini adalah usia, pekerjaan, paritas, dan lama penggunaan. Analisis dilakukan dengan menggunakan analisis chi square.Teknik pengambilan sampel yang digunakan ialah purposive sampling, dengan sampel sebanyak 81 akseptor. Hasil yang didapatkan ialah sebagian besar akseptor berusia 20-35 tahun, bekerja sebagai ibu rumah tangga dan mempunyai lebih dari 2 anak. Tidak terdapat hubungan antara usia akseptor terhadap kejadian risiko obesitas ( $\mathrm{p}=0,806 ; \mathrm{OR}=1,133 ; \mathrm{CI} 95 \%=0,419-3,060)$. Namun, terdapat hubungan antara lama penggunaan terhadap kejadian risiko obesitas $(\mathrm{p}=0,001$; OR=26,3; CI 95\% $=6,828$ 101,36). Hal tersebut mengindikasikan bahwa semakin lama kontrasepsi suntik digunakan akan meningkatkan kejadian risiko obesitas.
\end{abstract}

Kata kunci: Lama penggunaan, kontrasepsi suntik 3 bulan DMPA, usia, risiko obesitas

\section{ABSTRACT}

Injectable contraception is a hormonal drug used to prevent pregnancy which is used by injecting the drug into fertile women. The used of hormonal contraception can increase body weight. This research was conducted to analyze the relationship between age and duration of Injectable contraception utilization on the risk of obesity. This research was an observational study with analytic cross sectional study design. The population in this study were all new acceptors of 3 month injectable contraception DMPA at Perumnas II Pontianak Public Health Care in January 2018 to March 2019. The variables of this study were age, status of job, number of children, and duration of Injectable contraception utilization.Variables were analyzed using chi square. The sampling technique used was purposive sampling, with 81 acceptors as samples. The results obtained are that most acceptors aged 20-35 years old, work as housewives and have more than 2 children. 
Apparently, there is no relationship between the age of the acceptor to the risk of obesity $(p=0,806 ;$ OR $=1,133 ; C I 95 \%=0,419-3,060)$. However, there was a relationship between of injectable contraception utilization on the risk of obesity ( $p=0,001 ; O R=26,3$; CI 95\%=6,828-101,36). This indicates that the longer used of injection contraception tend to increases the risk of obesity.

Keywords: Duration of use, 3 month injectable contraception DMPA, age, the risk of obesity

\section{PENDAHULUAN}

Obesitas merupakan akumulasi lemak di dalam tubuh manusia yang melebihi jumlah yang diperlukan untuk fungsi normal tubuh. Hal ini dapat terjadi akibat peningkatan berat badan yang terus menerus (Aktar et al., 2017). Obesitas dikaitkan dengan banyak komorbiditas, seperti diabetes melitus, dislipidemia, obstructive sleep apnea, kanker tertentu dan yang paling utama ialah penyakit kardiovaskuler (Maria dan Evagelia, 2009). Faktor yang berkaitan dengan terjadinya obesitas selain asupan makanan dan pola hidup ialah penggunaan kontrasepsi hormonal (Pratiwi et al., 2004) terutama kontrasepsi hormonal suntik Depo Medroxy Progesterone Acetate (DMPA) (Zerihun et al., 2019).

Kontrasepsi suntik DMPA merupakan salah satu jenis kontrasepsi hormonal yang diberikan setiap 3 bulan dan paling banyak digunakan di Indonesia. Berdasarkan data Survei Demografi dan Kesehatan Indonesia (SDKI) tahun 2017 dengan besar persentase $29 \%$ dari 57,2\% peserta KB yang memilih metode KB modern (BKKBN, 2018). Kontrasepsi suntik banyak digemari dikarenakan praktis dalam penggunaannya, tetapi terdapat beberapa efek samping yang tidak diinginkan seperti kenaikan berat badan. Apabila hal ini tidak dikontrol maka dapat menyebabkan peningkatan berat badan terus menerus yang berisiko obesitas.

Efek peningkatan berat badan pada akseptor kontrasepsi DMPA ini dapat dirasakan setelah penggunaan minimal 6 bulan (Cunningham, 2005). Selain itu, dilaporkan juga oleh Wolrd Health Organization (WHO) seperti yang dikutip oleh Cunningham, yaitu pada tahun pertama penggunaan terjadi peningkatan berat badan rata-rata sebesar $2,7 \mathrm{Kg}$, pada tahun kedua terjadi peningkatan berat badan rata-rata sebesar $4 \mathrm{Kg}$, dan pada tahun ketiga terjadi peningkatan berat badan rata-rata sebesar $7 \mathrm{Kg}$ (Ambarwati and Sukarsi, 2012). Pernyataan tersebut menunjukkan bahwa terdapat kaitan antara lama penggunaan terhadap peningkatan berat badan yang berisiko terjadinya obesitas. Penelitian ini 
diperlukan untuk menganalisis hubungan lama penggunaan dan usia akseptor terhadap kejadian risiko obesitas pada akseptor suntik 3 bulan DMPA di Puskesmas Perumnas II Pontianak.

\section{METODE PENELITIAN}

Penelitian ini termasuk penelitian observasional dengan menggunakan rancangan penelitian potong lintang (cross sectional) retrospektif. Teknik pengambilan sampel menggunakan teknik purposive sampling, dimana mengambil sampel berdasarkan kriteria tertentu yaitu kritesia inklusi dan eksklusi. Kriteria inklusi dari penelitian ini ialah akseptor kontrasepsi suntik 3 bulan DMPA yang memiliki data rekam medis di Puskesmas Perumnas II Pontianak, wanita yang sudah menikah berusia 15-49 tahun, minimal penggunaan suntik 3 bulan DMPA selama 6 bulan. Kriteria eksklusi dari penelitian ini ialah sedang menggunakan obat pelangsing, sedang melakukan program diet penurunan berat badan, terdapat riwayat obesitas, menggunakan kontrasepsi hormonal lainnya seperti implan, pil KB, Intrauterine Device (IUD) dan lainnya, dan akseptor yang berpindah-pindah fasilitas kesehatan untuk penggunaan kontrasepsi suntik.

\section{Instrumen Penelitian}

Instrumen penelitian yang digunakan ialah lembar pengumpul data, rekam medis, dan laptop.

\section{Jalannya Penelitian}

Studi dilakukan dengan pengambilan data faktor dan risiko pada satu kali waktu yang menggunakan data rekam medis. Penelitian ini menggunakan data rekam medis akseptor yang menggunakan suntik 3 bulan DMPA dari bulan Januari 2018-Maret 2019 terhitung sejak awal penggunaan suntik 3 bulan DMPA. Penelitian dilakukan di Ruang Rekam Medis Poli Kesehatan Ibu dan Anak (KIA) Puskesmas Perumnas II Pontianak. Sampel minimal yang digunakan pada penelitian ini ialah sebesar 79 sampel, berikut proses perhitungan menggunakan rumus Lemeshow, seperti terlihat pada persamaan 1 .

$$
n=\frac{\mathrm{N} \cdot\left(Z^{2} 1-\frac{\alpha}{2}\right) \cdot p \cdot q}{d^{2}(\mathrm{~N}-1)+\left(Z^{2} 1-\frac{\alpha}{2}\right) \cdot p \cdot q}
$$




$$
\begin{aligned}
& n=\frac{139 \cdot(1,96)^{2} \cdot 0,137 \cdot(1-0,137)}{0,05^{2}(139-1)+(1,96)^{2} \cdot 0,137(1-0,137)} \\
& n=\frac{73,1555 \cdot(0,863)}{0,345+0,4541} \\
& n=\frac{63,133}{0,7991} \\
& n=79 \text { sampel }
\end{aligned}
$$

\section{Analisis Data}

Data yang diperoleh dikelompokkan berdasarkan kategori variabel independen yaitu usia serta lama penggunaan dan variabel dependen ialah kejadian risiko obesitas. Analisis yang dilakukan berupa analisis univariat dan bivariat. Analisis univariat dilakukan menggunakan microsoft excel untuk menganalisis distribusi frekuensi data dan analisis bivariat dilakukan dengan menggunakan software Statistical Package for the Social Science (SPSS versi 25) dengan uji Chi-square. Hal ini dilakukan untuk menganalisis hubungan antara variabel independen dan dependen dan untuk melihat peluang terjadinya kejadian dengan mengetahui nilai Odds Ratio(OR). Nilai p dinyatakan signifikan bila $\mathrm{p}<0,05$.

\section{HASIL DAN PEMBAHASAN}

Karakteristik akseptor dari penelitian ini terlihat pada Tabel I.

Tabel I. Karakteristik Akseptor ( $\mathrm{N}=81)$

\begin{tabular}{lll}
\hline Karakteristik & Jumlah & Persentase (\%) \\
\hline Usia akseptor(tahun) & & \\
b. $20-35$ & 58 & 71,6 \\
c. $>35$ & 23 & 28,4 \\
Pekerjaan & & \\
a. IRT & 79 & 97,5 \\
b. Swasta & 2 & 2,5 \\
Paritas(anak) & & \\
a. $\geq 2$ anak & 63 & 77,8 \\
b. $<2$ anak & 18 & 22,2 \\
\hline
\end{tabular}

Hasil penelitian didapatkan akseptor yang paling banyak menggunakan kontrasepsi suntik 3 bulan ialah rentang usia 20-35 tahun. Hal ini sesuai dengan teori dari Badan Kependudukan dan Keluarga Berencana Nasional (BKKBN) yang menyatakan bahwa 
usia 20-35 tahun ialah usia yang lebih aman dari kematian maternal sehingga pada kelompok usia tersebut dianjurkan untuk menggunakan kontrasepsi dapat mengurangi risiko kematian pada bayi (Suratun, 2013). Selain itu, pada usia 20-35 tahun merupakan masa menjarangkan kehamilan sehingga banyak akseptor menggunakan KB untuk hal ini (Septianingrum et al., 2018). Ibu Rumah Tangga (IRT) merupakan pekerjaan dominan pada peserta KB. Pemilihan suntik 3 bulan dengan kandungan DMPA menjadi pilihan yang tepat. Alasannya penggunaannya yang praktis, dimana penyuntikkan hanya dilakukan setiap 3 bulan sekali (Amran and Damayanti, 2018). Walaupun demikian, efek samping dari penggunaan DMPA jangka panjang berisiko untuk terjadinya obesitas. Melihat kondisi tersebut, jika akseptor DMPA memiliki aktivitas fisik yang rendah berpotensi untuk terjadinya kenaikan berat badan dengan cepat hingga obesitas (Nurcahyo, 2011). Akseptor yang memiliki $\geq 2$ anak cenderung menggunakan DMPA karena lebih praktis dan nyaman dalam mencegah kehamilan atau membatasi jumlah anak (Speroff and Fritz, 2011). Menurut Speroff and Fritz,(2011) bahwa jumlah anak yang pernah dilahirkan (paritas) memiliki hubungan dengan peningkatan berat badan, yaitu semakin sering melahirkan maka risiko obesitas semakin besar. Hal ini dikarenakan wanita yang sering melahirkan sering terpapar hormon kehamilan terutama progesteron yang dapat menyebabkan retensi insulin bahkan intoleransi glukosa (Hidayati dan Lorenza, 2019).

Tabel II. Hubungan kelompok lama penggunaan dengan kejadian risiko obesitas

\begin{tabular}{|c|c|c|c|c|c|c|c|c|}
\hline \multirow{3}{*}{$\begin{array}{l}\text { Lama } \\
\text { Penggunaan }\end{array}$} & \multicolumn{4}{|c|}{ Risiko Obesitas } & \multirow{3}{*}{$\begin{array}{c}p- \\
\text { value }\end{array}$} & \multirow{3}{*}{ OR } & \multicolumn{2}{|c|}{ CI 95\% } \\
\hline & \multicolumn{2}{|c|}{ Ya } & \multicolumn{2}{|c|}{ Tidak } & & & \multirow{2}{*}{ Lower } & \multirow{2}{*}{ Upper } \\
\hline & $\mathbf{N}$ & $\%$ & $\mathbf{N}$ & $\%$ & & & & \\
\hline$\geq 12$ bulan & 27 & 90 & 13 & 25,5 & ref & 26.3 & 6.828 & 101,36 \\
\hline 6-11 bulan & 3 & 10 & 38 & 74,5 & 0,001 & & & 2 \\
\hline
\end{tabular}

Keterangan: ref= Pembanding (kelompok berisiko), OR= Oddratio, $\mathrm{CI}$ 95\%= Confident Interval

Tampak pada Tabel II, bahwa kejadian risiko obesitas cenderung terjadi pada kelompok $\geq 12$ bulan (90\%) dibanding kelompok $<12$ bulan (10\%). Kejadian risiko obesitas pada kelompok lama penggunaan $\geq 12$ bulan 26,3 kali lebih tinggi dibandingkan dengan kelompok lama penggunaan $<12$ bulan. Perbedaan kedua kelompok secara statistik bermakna signifikan ( $\mathrm{p}=0,001 ; \mathrm{OR}=26,3$; CI95\%=6,828-101,36). Penggunaan 
DMPA yang singkat atau di bawah 12 bulan dikarenakan akseptor merasakan munculnya efek samping dari penggunaan DMPA. Efek samping yang dirasakan berupa perubahan berat badan, gangguan haid, depresi, keputihan, jerawat dan sebagainya. Efek samping yang paling dominan terjadi ialah kenaikan berat badan (Rahayu and Wijanarko, 2017). Berbeda halnya dengan hasil penelitian Hasan yang menyatakan bahwa penggunaan kontrasepsi hormonal tidak memiliki hubungan dengan kejadian obesitas pada wanita subur (Hasan et al., 2013). Hasil penelitian Hadina et al., (2020) menyimpulkan bahwa terdapat hubungan yang bermakna antara waktu penggunaan DMPA terhadap peningkatan Indeks Massa Tubuh (IMT) dengan nilai $\mathrm{p}=0,001(\mathrm{p}<0,05)$ (Hadina et al., 2020). Hasil ini juga sesuai dengan hasil penelitian Moloku et al., (2016) mengatakan bahwa terdapat hubungan yang signifikan antara lama penggunaan DMPA terhadap kenaikan IMT yang ditunjukkan dari nilai $p=0,004(p<0,05)$. Beberapa penelitian lainnya menunjukkan hasil yang sama bahwa kenaikan IMT lebih cepat pada akseptor yang menggunakan DMPA dibandingkan dengan yang tidak menggunakan DMPA (Sutriani,2017). Kenaikan berat badan terjadi sekitar 1 sampai $5 \mathrm{Kg}$ dalam satu tahun pertama (Purnamasari, 2009).

Peningkatan IMT terjadi pada akseptor yang menggunakan DMPA dikarenakan kandungan hormon progesteron dapat meningkatkan nafsu makan. Penggunaannya dengan dosis tinggi dan dalam waktu yang lama berisiko untuk terjadinya peningkatan IMT. Di sisi lain, peningkatan nafsu makan disebabkan adanya gangguan pada saraf pusat di hipotalamus (Purnamasari, 2009). Timbunan lemak dalam tubuh disebabkan banyaknya hormon progestin sehingga memudahkan dalam mengubah karbohidrat dan gula menjadi lemak sehingga lemak di bawah kulit bertambah. Di sisi lain, penggunaan DMPA dalam jangka panjang akan berpengaruh terhadap kadar estrogen level terendah. Hilangnya estrogen dalam sirkulasi menyebabkan peningkatan berat badan (Glacier, 2006). Hal ini terjadi karena estrogen merupakan faktor utama dalam meregulasi metabolisme adiposit atau sel lemak sehingga terjadi peningkatan IMT. Kenaikan berat badan pada akseptor hormonal dikarenakan oleh paparan hormon. Paparan terhadap berbagai macam hormon dapat mempengaruhi metabolisme dan perkembangan sel adiposit, misalnya hormon progesteron dan estrogen. Peran hormon estrogen yaitu dalam memetabolisme lipid dan karbohidrat. Estrogen dapat meregulasi distribusi lemak tubuh, 
berinteraksi dengan sinyal adiposa (leptin) yang disampaikan ke otak, memfasilitasi mobilisasi lemak viseral, dan deposisi lemak subkutan (Fitriani, 2018).

Tabel III. Hubungan kelompok usia dengan kejadian risiko obesitas pada akseptor

\begin{tabular}{|c|c|c|c|c|c|c|c|c|}
\hline \multirow{3}{*}{ Usia Akseptor } & \multicolumn{4}{|c|}{ Risiko Obesitas } & \multirow{3}{*}{$\begin{array}{c}p- \\
\text { value }\end{array}$} & \multirow{3}{*}{ OR } & \multicolumn{2}{|c|}{ CI $95 \%$} \\
\hline & \multicolumn{2}{|c|}{ Ya } & \multicolumn{2}{|c|}{ Tidak } & & & & $\mathbf{U}$ \\
\hline & $\mathbf{N}$ & $\%$ & $\mathbf{N}$ & $\%$ & & & Lower & Upper \\
\hline $\begin{array}{l}>35 \text { tahun } \\
20-35 \text { tahun }\end{array}$ & $\begin{array}{c}9 \\
21\end{array}$ & $\begin{array}{l}30 \\
70\end{array}$ & $\begin{array}{l}14 \\
38\end{array}$ & $\begin{array}{l}27,5 \\
72,5\end{array}$ & $\begin{array}{c}r e f \\
0,806\end{array}$ & 1,133 & 0,419 & 3,060 \\
\hline
\end{tabular}

Keterangan: $r e f=$ Pembanding(kelompok berisiko), OR= Oddratio, $\mathrm{CI} 95 \%=$ Confident Interval

Berdasarkan Tabel III diperoleh bahwa kejadian risiko obesitas banyak terjadi pada kelompok usia 20-35 tahun (70\%) dibanding kelompok usia $>35$ tahun (30\%). Namun pada hasil penelitian ini, faktor usia tidak memiliki hubungan dengan kejadian obesitas ( $\mathrm{p}=0,806)$. Hasil ini sesuai dengan hasil penelitian Sikalak et al., (2017) yang menyatakan bahwa tidak terdapat hubungan antara usia dan kejadian obesitas dengan hasil nilai $\mathrm{p}=0,707$ ( $\mathrm{p}<0,05)$ (Sikalak et al., 2017). Hasil ini sejalan juga dengan hasil penelitian Novitasary et al.,(2013) menunjukkan bahwa pada rentang usia 30-49 lebih banyak yang tidak obesitas daripada yang obesitas (Novitasary et al., 2013). Walaupun demikian, sebagian besar usia >35 tahun mengalami kenaikan IMT, tetapi tidak masuk kategori obesitas. Faktor lainnya diduga ialah lama penggunaan, akseptor yang berusia $>35$ tahun sebagian besar menggunakan suntik 3 bulan DMPA $<12$ bulan. Lama penggunaan berperan signifikan terhadap kejadian risiko obesitas. Pada lama penggunaan $<12$ bulan untuk usia >35 tahun hanya $15 \%$ yang berisiko obesitas, sedangkan lama penggunaan $\geq 12$ bulan untuk usia $>35$ tahun sebanyak $70 \%$ berisiko obesitas. Hal ini menunjukkan bahwa usia $>35$ tahun dengan lama penggunaan $\geq 12$ bulan diduga meningkatkan risiko kejadian obesitas. Penelitian ini menggunakan data rekam medis sehingga terdapat beberapa faktor yang tidak dapat dikontrol yang mana dapat juga menyebabkan peningkatan berat badan, seperti aktivitas fisik, asupan makanan, tingkat stress, dan durasi tidur. Selain itu, teknik pengambilan sampel purposive sampling menyebabkan representasi hasil penelitian ke populasi hanya berlaku pada akseptor yang sesuai dengan kriteria inklusi dan ekslusi dari penelitian ini. 


\section{KESIMPULAN}

Lama penggunaan kontrasepsi suntik 3 bulan DMPA memiliki hubungan bermakna dengan kejadian risiko obesitas pada akseptor kontrasepsi suntik 3 bulan DMPA di Puskesmas Perumnas II Pontianak dengan $p$ value $=0,001$; OR=26,308; CI 95\% Lower= 6,828 dan Upper $=101,362$. Berbeda halnya dengan usia akseptor tidak memiliki hubungan bermakna dengan kejadian risiko obesitas pada akseptor kontrasepsi suntik 3 bulan DMPA di Puskesmas Perumnas II Pontianak dengan $p$ value=0,806; OR=1,133; CI 95\% Lower $=0,419$ dan Upper $=3,060$.

\section{UCAPAN TERIMAKASIH}

Terimakasih kepada Program Studi Farmasi Fakultas Kedokteran Universitas Tanjungpura Pontianak dan Puskesmas Perumnas II Pontianak yang telah memberikan kesempatan kepada peneliti untuk dapat menyelesaikan penelitian ini.

\section{DAFTAR PUSTAKA}

Aktar, N., Qureshi, N. K., \& Ferdous, H. S. (2017). A review of pathogenesis and management strategies in adult. Delta Medical College Journal, 5(1), 35-48.

Ambarwati,W.N., \& Sukarsi, N. (2012). Pengaruh kontrasepsi hormonal terhadap berat badan dan lapisan lemak pada akseptor kontrasepsi suntik DMPA di polindes Mengger Karanganyar Ngawi. Jurnal Kesehatan, 5(2), 93-102.

Amran, Y., \& Damayanti, R. (2018). Hubungan antara motivasi keluarga berencana dan persepsi terhadap alat kontrasepsi dengan pola penggantian metode kontrasepsi di Nusa Tenggara Barat. Jurnal Kesehatan Reproduksi, 9(1), 59-67.

BKKBN. (2018). Survey demografi dan kesehatan Indonesia. BPS BKKBN DepKes: Jakarta.

Cunningham. (2005). Obstetri Williams. EGC: Jakarta. 
Fitriani, D. (2018). Peran estrogen dan leptin dalam Homeostasis energi. Jurnal Ilmu Kedokteran Dan Kesehatan, 5(2), 123-131.

Glacier, A. (2006). Keluarga berencana dan kesehatan reproduksi. EGC: Jakarta.

Hadina, Hadriani, Kartini, \& Putri Nurul Sakinah. (2020). Waktu penggunaan depo medroxy progesterone acetate terhadap peningkatan indeks massa tubuh (IMT) ibu. Poltekita : Jurnal Ilmu Kesehatan, 13(2), 76-80.

Hasan, M., Nelly Mayulu, \& Kawengian, S. (2013). Hubungan penggunaan kontrasepsi hormonal dengan obesitas pada wanita usia subur(WUS) di puskesmas Wawonasa Kecamatan Singkil Manado. Jurnal E-Biomedik, 1(2), 946-950.

Hidayati, H., \& Lorenza, N. (2019). Lama penggunaan kontrasepsi depo medroxy progesterone acetate dengan citra tubuh. Jurnal Kesehatan, 10(2), 70-75.

Maria, P., \& Evagelia, S. (2009). Obesity Disease. Health Science Journal, 3(3), 132139.

Moloku, M., Hutagaol, E., \& Masi, G. (2016). Hubungan lama pemakaian lama kontrasepsi suntik 3 bulan dengan perubahan berat badan di Puskesmas Ranomuut Manado. Jurnal Keperawatan, 4(1), 1-8.

Novitasary, M. D., Mayulu, N., \& Kawengian, S. E. (2013). Hubungan antara aktivitas fisik dengan obesitas pada wanita usia subur peserta Jamkesmas di Puskesmas Wawonasa Kecamatan Singkil Manado. EBiomedilk, 1(2), 1040-1046.

Nurcahyo, F. (2011). Kaitan antara obesitas dan aktifitas fisik, medikora. Medikora, 7(1), 87-96.

Pratiwi, D., Syahredi, S., \& Erkadius, E. (2004). Hubungan antara penggunaan kontrasepsi hormonal suntik DMPA dengan peningkatan berat badan di Puskesmas 
Lapai Kota Padang. Jurnal Kesehatan Andalas, 3(3), 365-369.

Purnamasari, D. (2009). Hubungan lama pemakaian KB suntik depo medroksi progesteron asetat (DMPA) dengan perubahan berat badan di BPS (Bidan Praktek Swasta) Yossi Trihana Jogonalan Klaten. Universitas Sebelas Maret.

Rahayu, T. B., \& Wijanarko, N. (2017). Efek samping akseptor KB suntik depo Medroksi Progesterone Acetate (DMPA) setelah 2 tahun pemakaian. Jurnal Kesehatan Samodra Ilmu, 8(1), 32-38.

Septianingrum, Y., Wardani, E. M., \& Kartini, Y. (2018). Faktor-faktor yang mempengaruhi tingginya akseptor KB suntik 3 bulan. Jurnal Ners Dan Kebidanan, 5(1), 15-19.

Sikalak, W., Widajanti, L., \& Aruben, R. (2017). Faktor-faktor yang berhubungan dengan kejadian obesitas pada karyawati perusahaan di bidang telekomunikasi Jakarta Tahun 2017. Jurnal Kesehatan Masyarakat, 5(3), 193-201.

Speroff, L., \& Fritz, M. A. (2011). Clinical Gynecologic Endocrinology and Infertility, Lippincott Williams \& Wilkins.

Suratun. (2013). Pelayanan keluarga berencana dan pelayanan kontrasepsi. Trans Info Media.

Zerihun, M. F., Malik, T., Ferede, Y. M., Bekele, T., \& Yeshaw, Y. (2019). Changes in body weight and blood pressure among women using depo-provera injection in northwest Ethiopia. BMC Research Notes, 12(512), 1-5. 